\title{
PREVALENCE OF DENTAL CARIES AMONG ADULTS AND ELDERLY IN AN URBAN POPULATION OF PUDUKKOTTAI, INDIA
}

\author{
Prabhu N1, Jeevitha T², Gayathri V³, Pirabu R.A4, Ram Prakash V5
}

\section{HOW TO CITE THIS ARTICLE:}

Prabhu N, Jeevitha T, Gayathri V, Pirabu R.A, Ram Prakash V. "Prevalence Of Dental Caries Among Adults And Elderly In An Urban Population Of Pudukkottai, India". Journal of Evolution of Medical And Dental Sciences 2013; Vol2, Issue 50, December 16; Page: 9806-9811.

ABSTRACT: BACKGROUND: Dental caries remains the most important dental health problem in developing countries. In India the prevalence of dental caries is reported to be about 50-60\%. Most of the Indian studies have been carried out in school children and very few in adults. This study aimed to estimate the prevalence of dental caries in the adult population (aged 35-44 years) and in the elderly (60 years and above) in an urban area in Pudukkottai, Tamilnadu, India.METHODOLOGY: A community-based cross-sectional study was carried out in Pudukkottai, from August - September 2013. The enrollment of participants in the 35-44 years age-group was $340(75.2 \%)$ and it was $112(24.8 \%)$ in those $\geq 60$ years. A local adaptation of the WHO questionnaire was used. Oral examination was done and dentition status was recorded by trained dental investigators and according to the standard procedures.RESULTS: A total of 452 participants were enrolled in the study. The prevalence of dental caries in the 35-44 years age-group was 82.5\% and it was $92.1 \%$ in those $\geq 60$ years. The DMF index was $5.7 \pm 4.7$ in the $35-44$ years age-group and $13.8 \pm 9.6$ in the $\geq 60$ years age-group. Of the participants, $27.9 \%$ were currently using tobacco. A statistically significant association was found between tobacco consumption and dental caries $(\mathrm{P}=$ 0.026). The awareness about good and bad dental practices was found to be low among the study participants. One-fifth of the individuals with dental problems relied on home remedies.CONCLUSION: The prevalence of dental caries among adults is high in this population. There is a need to generate awareness about oral health and the prevention of dental caries and to institute measures for the provision of dental care services at the primary level.

KEYWORDS: Community-based estimate, dental caries, prevalence, Questionnaire survey, Pudukkottai.

INTRODUCTION: Oral health means more than just good teeth; it also means being free of chronic pain in the mouth or in the facial region; the absence of oral and throat cancer, oral sores, and birth defects such as cleft lip and palate; freedom from periodontal (gum) disease, tooth decay and tooth loss, or the many other diseases and disorders that affect the mouth and oral cavity. ${ }^{1}$ Oral health is an integral component of general health and is essential for well-being. There is evidence to prove the interrelationship between oral and general health. ${ }^{2}$

Many general health conditions have oral manifestations that increase the risk of oral disease which, in turn, is a risk factor for many systemic diseases, such as diabetes, cardiovascular diseases, etc. However, the wider meaning of oral health does not diminish the relevance of the two globally leading oral afflictions: dental caries and periodontal diseases. Despite great successes in improving the oral health of populations globally, problems still remain in many communities around the world, particularly among the underprivileged groups in developing countries. Dental 


\section{ORIGINAL ARTICLE}

caries and periodontal diseases have historically been considered an important component of the global disease burden. Both can be effectively prevented and controlled through a combination of community, professional, and individual actions. Early detection of disease is, in most cases, crucial to control of the oral condition. A thorough naked-eye oral examination with adequate light can identify many oral conditions in the early stages.

Dental caries is the major oral health condition in developing countries, affecting $60-90 \%$ of the school children and the vast majority of adults. ${ }^{3}$ In India, the prevalence of dental caries is reported to be 50-60\%.4 Most of the Indian studies that have been published focused on school children $^{5-11}$ and only a few studies have been done among adults. ${ }^{12-13}$ The World Health Organization recommends basic oral health surveys in five selected age-groups (i.e., 5 years, 12 years, 17-18 years, 35-44 years, and 65-74 years) ${ }^{14}$ in order to estimate the magnitude of the problem and to plan intervention activities. Therefore, keeping in mind the paucity of literature on dental problems in adults and the public health importance of dental caries, this study was planned to provide some information on the oral health needs of the adult population in an urban area in Pudukkottai.

OBJECTIVES: The present study was carried out with the following objectives:

1. To estimate the prevalence of dental caries in the selected age-groups in the study area.

2. To study the knowledge, beliefs, and practices of the community with regard to dental health problems.

3. To identify the dental care-seeking behavior of the community.

MATERIALS AND METHODS: A cross-sectional community-based survey was conducted at Pudukkottai, Tamilnadu which is a urban area; it is also the field practice area of Dr. Muthulakshmi memorial Government Head Quarters Hospital, Pudukkottai. Eight different areas in the town were selected and included in this study, and if necessary dental primary care and curative services are recommended to the individuals. The study was conducted from August - September 2013.

The sample size, calculated on the basis of the prevalence of dental caries of $60 \% 4$ and absolute precision of 5 , was 384 . Assuming a nonresponse rate of approximately $10 \%$, we aimed to enroll 452 individuals from the community. Three out of the eight areas were selected randomly for the purpose of this study. According to the recommendations by WHO, for a basic oral health survey, we decided to take two adult age-groups for this study, i.e., 35-44 years and $\geq 60$ years. The enrollment of participants in the 35-44 years age-group was 340 (75.2\%) and it was 112 (24.8\%) in those $\geq 60$ years. Participants were enrolled by house-to-house visits, using the consecutive sampling technique. A pre-tested questionnaire ${ }^{15}$ (a local adaptation of WHO's standard oral health questionnaire) consisting of questions on personal details, oral hygiene practices, dental problems and care-seeking behavior was used in the survey. The questionnaire was administered by the investigators and was followed by a naked-eye oral examination for dentition status, using an oral probe and mirror by the junior dental surgeon.

Data was collected by two survey teams. All members of the data collection teams received training to enable them to identify common dental morbidities; the training included classroom lectures and observation and practical sessions held at the Prakash Dental Clinic and Research centre, Pudukkottai, under close supervision of the specialists. A senior resident or another faculty member monitored the daily data collection process to ensure quality control. All questionnaires and data forms were checked for completeness and consistency, and when necessary, the 


\section{ORIGINAL ARTICLE}

investigators made additional field visits to clarify entries. In addition, $5 \%$ of the data was crosschecked by the supervisors through field visits.

Ethical issues: The study participants were given clear explanations about the objective of the study and verbal informed consent was taken. Those who required dental care were referred to the mobile clinic or to the dental OPD in Prakash Dental Clinic and Research Centre, Pudukkottai. It was ensured that adequately sterilized instruments were used for oral examination to prevent cross-infection.

Data entry and analysis: Data that was obtained was entered in an MS-Excel spreadsheet and analyzed using SPSS 10.0 software. The Chi-square test was applied to examine the association, if any, between dental caries and various factors. The DMF score and the DMFT index were calculated.

RESULTS: A total of 151 houses were visited by the survey team. With a non-participation rate of $6.7 \%$ (36 houses were found locked on two consecutive visits and, in 7 houses, 12 eligible individuals refused to participate), 565 households were enrolled into the study. The total number of eligible people enrolled in the study was 452. [Table-1] describes the age and sex distribution of the participants. About two-thirds of the participants were females. There were approximately thrice as many participants in the age-group of 35-44 years as compared to the $\geq 60$ year age-group.

Oral hygiene practices: It was found that $95.6 \%$ of the participants brushed their teeth daily. Among those who brushed daily, over half (78.2\%) of the participants reported brushing their teeth for more than $2 \mathrm{~min}$. There were 377 (83.4\%) study participants who used toothpaste and another $67(14.8 \%)$ who used toothpowder for brushing. Only eight (1.8\%) participants reported using material other than toothpaste or toothpowder; the commonly used alternatives included neem tree extracts, coal powder, brick powder, etc. There were 114 (25.2\%) individuals who were current users of some form of tobacco. Among the tobacco users, 75 (65.7\%) were smokers, while 39 $(34.3 \%)$ used the smokeless form of tobacco. There were 19 individuals (16.6\%) who were used both smoked and smokeless forms of tobacco.

Dental problems and care-seeking behavior: About three-fourths - 328 (72.5\%) of the participants had experienced some dental problem in the past one year. The proportion of individuals who had had a dental problem in the past one year was found out be $73.6 \%$ and $80.4 \%$ in the age-groups of 35-44 and $\geq 60$ years, respectively. Among those who had encountered a dental health problem in last one year, $78.6 \%$ sought medical help and the remaining $21.4 \%$ relied on home remedies. One-third of those who sought medical help for dental problem, visited a public health facility (dispensary, hospital,) and rest went to a private health care facility.

Less than half (49.6\%) of the study participants were aware of any one of the good practices for maintaining dental health, e.g., brushing teeth, periodic dental check-up, etc. Over one-third $174(38.5 \%)$ of the participants knew about practices that are bad for the teeth, such as eating too much of sweet, excess sugar, sweetened drinks, etc. About one-fourth of the participants have awareness that regular dental check-ups are important for good dental health.

Dental examination: Oral examination of all the participants showed a prevalence of dental caries of $87.2 \%$. The proportion of individuals with caries was higher in the age-group of $\geq 60$ years as 


\section{ORIGINAL ARTICLE}

compared to the age-group of $35-44$ years $(92.1 \%$ vs $82.5 \%)$ and this difference was found to be statistically significant [Table-2]. However, analysis of dental caries by sex showed that there was no statistically significant difference between males and females [Table-2]. A statistically significant association was found between tobacco consumption and dental caries $(P=0.026)$ as shown in [Table-4].

The mean DMF score of study population was found out to be 7.9 with a standard deviation of 8.1. The mean DMF score varied across the age-groups, that is, it was 5.7 (4.7) and 13.8 (9.6) among the $35-44$ years and the $\geq 60$ years age-groups, respectively.

DISCUSSION: In the present study, there were more female (308) participants than males (144) [68.1\% vs 31.9\%]. The reason may be because the survey timings coincided with working hours and, therefore, the men could not be contacted; the majority of the participants were housewives.

The prevalence of dental caries in the age-group of 35-44 years in the present study was found to be $82.4 \%$, which is lower than that reported in the WHO Oral Health Country Profile (94\%).[16] However, the results were found to be higher in other studies ${ }^{17,18}$ compared to the present investigation in the age-group of 35-40 years.

The prevalence of dental caries in the age-group of 60 years and above in this study was 91.9\%. This was seen to be higher than that reported in other studies ${ }^{16,12}$. A study from South India among the elderly reported a mean DMF index of $13.5,{ }^{13}$ which is similar to that reported in the present study (13.8). The differences in the prevalence rates may be due to the different study settings.

\section{Limitations:}

1. The majority of the study participants were females. This might bias the study results, as the sample taken is not representative of the population.

2. There were multiple investigators involved in collecting the data and carrying out the oral examinations; though they were all trained to carry out the procedures, some amount of interobserver variation cannot be ruled out. Therefore, the interpretation of the results of this study should be made keeping the above limitations in mind.

CONCLUSION: This study showed that the prevalence of dental caries remains high among the age group of elderly persons. The awareness about good and bad dental practices was found out to be low among the study participants. More than One-fifth of the individuals with dental problems relied on home remedies and thus neglected dental care. This study reveals that there is a need for accessible and affordable oral health services to be provided to this urban community. This can be in the form of oral health education in the community and school settings to create awareness about oral health in the general population. Simultaneously, services for oral health care at the primary level can be established in order to bring oral health care to the doorsteps of the people. This will need to be supported by referral mechanisms for those who need specialized treatment in secondary or tertiary centers. Further, this study will be extended to the school students to understand the pathophysiological details about the microorganisms involved in the dental caries, need of following good health practices and regular dental checkups. 


\section{ORIGINAL ARTICLE}

\section{REFERENCES:}

1. http://www.who.int/mediacentre/factsheets/fs318/en/index.html.

2. Grossi SG, Genco RJ. Periodontal disease and diabetes mellitus: A two-way relationship. Ann Periodontol 1998;3:51-61.

3. The World Oral Health report 2003.

4. Naseem Shah. Oral and dental diseases: Causes, prevention and treatment strategies: Burden of disease, National Commission on Macroeconomics and Health; 2005. p. 275-98.

5. Vecher BR. Dental Survey of school children in Amritsar. J Ind Dent Assoc 1952;24:2-8.

6. Dutta A. Study on the prevalence of periodontal and dental caries amongst school going children. J Ind Dent Assoc 1965;37:12-5.

7. Saravanan S, Madivanan I, Subashini B, Felix JW. Prevalence pattern of dental caries in the primary dentition among school children. Indian J Dent Res 2005;16:140-6.

8. Mahejabeen R, Sudha P, Kulkarni SS, Anegundi R. Dental caries prevalence among preschool children of Hubli: Dharwad city. J Indian SocPedodPrev Dent 2006;24:19-22.

9. Acharya S. Dental caries, its surface susceptibility and dental fluorosis in South India. Int Dent J 2005;55:359-64.

10. David J, Wang NJ, Astrom AN, Kuriakose S. Dental caries and associated factors in 12-year-old schoolchildren in Thiruvananthapuram, Kerala, India. Int J Pediatr Dent 2005;15:420-8.

11. Mahesh Kumar P, Joseph T, Varma RB, Jayanthi M. Oral health status of 5 years and 12 years school going children in Chennai city: An epidemiological study. J IndSocPedodPrev Dent 2005;23:17-22.

12. Shah N, Sundaram KR. Impact of socio-demographic variables oral hygiene practices oral habits and diet on dental caries experience of Indian elderly: A community-based study. Gerodontol 2004;21:43-50.

13. Thomas S, Raja RV, Kutty R, Strayer MS. Pattern of caries experience among an elderly population in south India. Int Dent J 1994;44:617-22.

14. Oral Health Surveys, Basic Methods. $4^{\text {th }}$ ed. 1997.

15. Prakash H, Duggal R, Mathur VP, Petersen PE. Manual for multi-centric oral health survey. WHO: India; 2004-05.

16. http://www.whocollab.od.mah.se/searo/india/data/indiacar.html.

17. Doifode VV, Ambadekar NN, Lanewar AG. Assessment of oral health status and its association with some epidemiological factors in population of Nagpur, India. Ind J Med Sci 2000;54:261-9.

18. Chakraborty M, Saha JB, Bhattacharya, Roy A, Ram R. Epidemiological correlates of dental caries in an urban slum of West Bengal. Ind J Pub Hlth 1997;41:56-67.

\begin{tabular}{|c|c|c|c|}
\hline Age group & Male & Female & Total \\
\hline 35- 44 years & $103(30.5)$ & $235(69.5)$ & 338 \\
\hline$\geq 60$ years & $41(36)$ & $73(64)$ & 114 \\
\hline Total & $144(31.8)$ & $308(68.2)$ & 452 \\
\hline
\end{tabular}

Table 1: Age and sex distribution of the study participants

Figures in parentheses are in percentage 


\section{ORIGINAL ARTICLE}

\begin{tabular}{|c|c|c|c|c|c|c|}
\hline \multirow{2}{*}{ Age group } & \multicolumn{3}{|c|}{ No. of individuals with dental caries } & \multicolumn{3}{|c|}{ No. of individuals without dental caries } \\
\hline & Male & Female & Total & Male & Female & Total \\
\hline $35-44$ years & $\begin{array}{c}107 \\
(38.4)\end{array}$ & $172(61.6)$ & 279 & $24(40.7)$ & $35(59.3)$ & 59 \\
\hline$\geq 60$ years & $32(30.5)$ & $73(69.5)$ & 105 & $4(44.4)$ & $5(55.6)$ & 9 \\
\hline Total & $139(36.2)$ & $245(63.8)$ & 384 & $28(41.2)$ & $40(58.8)$ & 68 \\
\hline
\end{tabular}

Figures in parentheses are in percentage

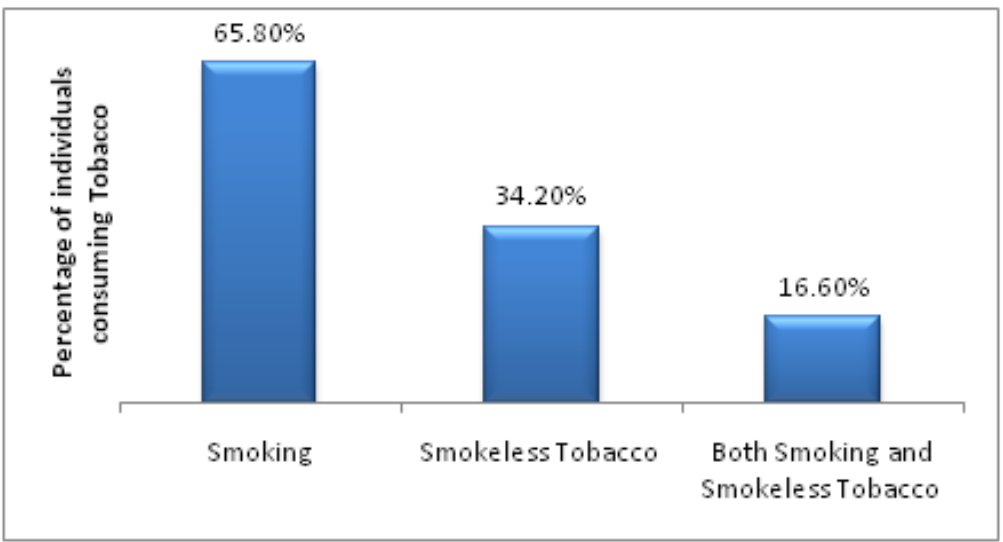

\section{Fig. 1: Association between Tobacco Consumption and Dental Caries}

\section{AUTHORS:}

1. Prabhu N.

2. Jeevitha $\mathrm{T}$.

3. Gayathri V.

4. Pirabu R.A.

5. Ram Prakash V.

\section{PARTICULARS OF CONTRIBUTORS:}

1. Research Associate, Department of Microbiology, Chennai Medical College Hospital and Research Centre, Tiruchirapalli, India.

2. Tutor, Department of Microbiology, Chennai Medical College Hospital and Research Centre, Tiruchirapalli, India.

3. PG Student, Department of Biotechnology, New Horizon College of Engineering, Bangalore, India.

4. Assistant Professor, Department of Community Medicine, Chennai Medical College Hospital and Research Centre, Tiruchirapalli, India.
5. Senior Dental Surgeon, Prakash Dental Clinic and Research Centre, Pudukkottai, India.

\section{NAME ADRRESS EMAIL ID OF THE CORRESPONDING AUTHOR:}

Dr. N. Prabhu,

Department of Microbiology,

Chennai Medical College Hospital and Research Centre,

Tiruchirapalli, India.

Email-leptoprabhu@gmail.com

Date of Submission: 08/11/2013.

Date of Peer Review: 20/11/2013.

Date of Acceptance: 29/11/2013.

Date of Publishing: 12/12/2013 